\title{
An Adaptive Current Quick Break Protection Based on Power Frequency Variation
}

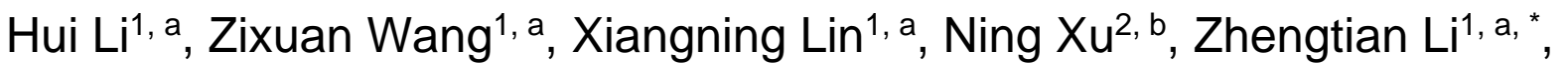 \\ Fanrong Wei, a , Siyi Liu ${ }^{1, a}$, Jinguang Huang ${ }^{2, b}$ \\ ${ }^{1}$ State Key Laboratory of Advanced Electromagnetic Engineering and Technology, School of \\ Electrical and Electronic Engineering, Huazhong University of Science and Technology Wuhan \\ 430000, China
}

${ }^{2}$ State Power Research Institute of Jiangxi electric power company, Jiangxi 330000, China

alihuiff1990@163.com, b645216440@qq.com

Keywords: R-SFCL, distance protection, power frequency variation distance relay.

\begin{abstract}
A mathematical model of resistance type superconducting fault current limiter (R-SFCL) is established and the influence to power frequency variation distance relay has been analyzed firstly. Then, it indicates that the input of the superconducting current limiter changes the circuit model before and after the fault, so that the power frequency variation impedance relay based on the pre fault memory data does not satisfy the superposition condition. An adaptive current quick break protection considering the impedance characteristics of superconducting current limiter is proposed, after the similarity and difference in principle and performance of the adaptive current quick break protection and power frequency variation impedance relay are discussed. Finally, the feasibility and effectiveness of the new method is verified by simulation in EMTDC/PSCAD.
\end{abstract}

\section{Introduction}

In recent years, with the development of high voltage and extra high voltage power grid and the expansion of power system scale, the phenomenon of short-circuit current exceeding standard becomes more and more serious, which brings great challenges to the security and stability of power system. At the same time, with the maturity of superconducting technology, superconducting fault current limiter has attracted worldwide attention due to its simple structure, detection / conversion / current limiting, multifunctional integration, fast current limiting speed and so on. [1,2].

The operation of the superconducting fault current limiter has brought challenges to the existing relay protection, especially to the correct operation of the distance protection.

As a power frequency variation impedance relay, the working voltage is calculated according to the power frequency sudden change voltage and current before and after the fault, and the rated voltage of the line or the normal voltage of the fault point is used as the braking voltage. Impedance calculation is not necessary, so it has a very high speed, while it has the directivity of impedance circle, does not respond to vibration, and has strong resistance to transition resistance, so it has been widely used [3]. However, the input of a fault current limiting device represented by a resistive superconducting fault current limiter is bound to change the line parameters, which brings new challenges to the protection based on the power frequency variation of voltage and current before and after the fault.

The mathematical model of the superconducting fault current limiter has been studied in the literature [4 6]. The superconducting fault current limiter can transition to a stable high impedance mode in a few milliseconds. Therefore, based on the setting method of the fixed current impedance of the superconducting fault current limiter, it can also meet the requirements of most of the relay protection. However, the existing power frequency impedance relay the fastest export time can reach 3 5 in milliseconds, whether the installment of R-SFCL will affect the power frequency impedance relay export time, need to be studied. The [7] based on the analysis of power frequency variation impedance relay mechanism and movement characteristics, pointed out that the power frequency 
variation impedance relay is essentially a special speed adaptive current protection, so the operating characteristic, the ability of transition resistance, the influence of the running state of the system is very similar to the adaptive current protection.

It must be noted that with the SFCL started on, the line parameters changed, which lead that electrical measurements before and after fault does not correspond to the same circuit model, resulting in power frequency variation protection based on memory element losing the superposition condition. This brings in problems difficult enough to subvert the basic principle of the power frequency variation protection, while the research on this aspect is still blank. On this basis, an adaptive current fast break protection scheme based on power frequency variation is proposed in this paper, which can well adapt to the current limiting impedance characteristics, and its speed and selectivity are no worse than power frequency variation distance relay. What's more, it has better capability of transition resistance, and provides a fast and reliable protection scheme for power systems installing current limiter.

\section{Working Principle}

When the power system fails, it can be decomposed into the superposition of the normal operation network and the fault network [8]. As shown in Fig. 1, the voltage and current state at fault can be decomposed into the state before the fault and the state of the fault component after fault.

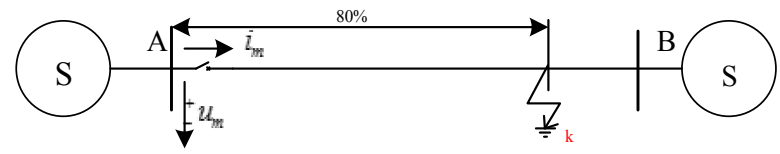

Fig. 1 fault analysis system

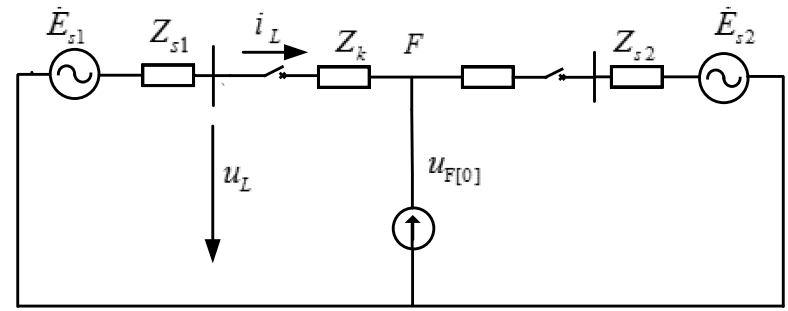

Fig. 2 equivalent circuit of power system before fault

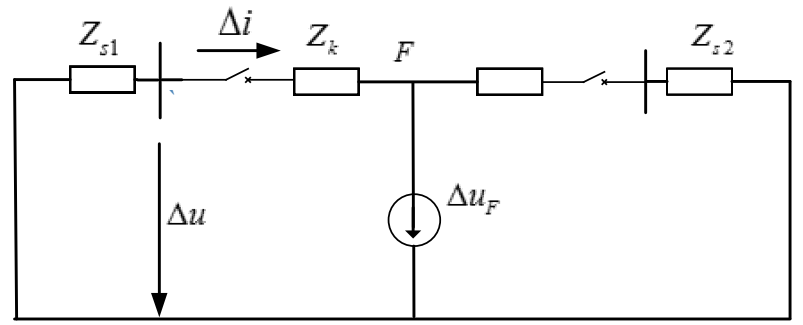

Fig. 3 equivalent circuit of fault component

In any mode of operation or operation, when the system fails, the voltage and current in the protection position meet the following formula:

$$
\left\{\begin{array}{l}
i_{m}=i_{L}+\Delta i \\
u_{m}=u_{L}+\Delta u
\end{array}\right.
$$

The physical meaning of the working voltage of an impedance relay is the change of the voltage at the end of the protection area before and after the fault. When the metal fault occurs, the voltage at fault is 0 . So the physical meaning is the voltage before the short circuit. Operation principle of impedance relay based on power frequency variation is as follow:

$$
\left|\Delta \dot{U}_{o p}\right|=\left|-\Delta \dot{I}_{m}\left(Z_{s 1}+Z_{s e t}\right)\right| \geq\left|\Delta \dot{U}_{F}\right|=U_{F|0|}
$$


The voltage of the short-circuit point is not very different from the rated voltage before the fault, and the rated voltage can simplify the calculation process, so the criterion of operation is usually written as:

$$
\left|\Delta \dot{U}_{o p}\right|=\left|-\Delta \dot{I}_{m}\left(Z_{s 1}+Z_{\text {set }}\right)\right| \geq k_{\text {rel }} \mathrm{U}_{N}
$$

$\mathrm{K}$ is the coefficient of reliability, with a range of 1.0 1.1.

\section{Impedance Characteristic of R-SFCL}

The impedance characteristics of R-SFCL can be approximated by a formula.

$$
R= \begin{cases}0 & t<t_{0} \\ R_{s c}\left(1-e^{-t / T_{s c}}\right) & t_{0}<t<t_{0}+T_{s c} \\ R_{s c} & t>t_{0}+T_{s c}\end{cases}
$$

Wherein, time $t_{0}$ starts SFCL, $t$ is the time after the failure occurs, and the $T_{s c}$ indicates the transition time from the RSFCL started to the stable resistance. When the superconducting fault current limiter is started, the resistance rises rapidly. R-SFCL quench at $1 \mathrm{~s}$, resistance characteristics shown in figure 4.

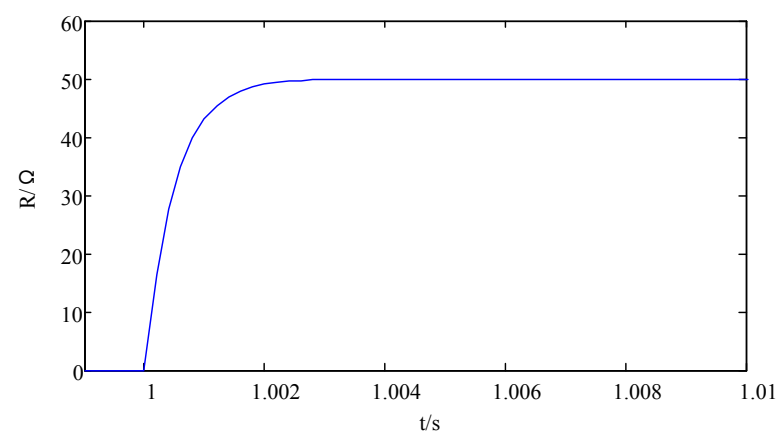

Figure 4 R-SFCL resistance characteristics

\section{Influence of R-SFCL on Power Frequency Variation Impedance Relay}

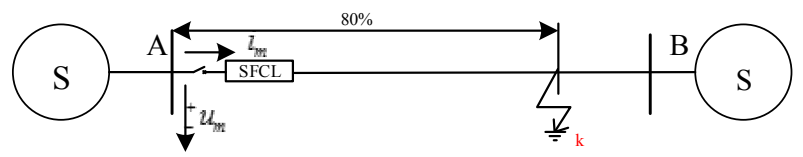

Fig. 5 double terminal power supply model

As shown in Fig. 5, the load current and voltage before the fault are respectively $i_{|0|}, u_{|0|}$, and the load current and voltage after the start of R-SFCL are respectively $i_{L}, u_{L}$.

$$
\begin{aligned}
& \dot{I}_{|0|}=\frac{\dot{E}_{1}-\dot{E}_{2}}{Z_{\mathrm{s} 1}+Z_{L}+Z_{\mathrm{s} 2}} \\
& \dot{I}_{L}=\frac{\dot{E}_{1}-\dot{E}_{2}}{Z_{\mathrm{s} 1}+Z_{L}+Z_{\mathrm{s} 2}+R_{f c l}}
\end{aligned}
$$

In the setting process of power frequency variable impedance relay, the fault component is subtracted from the current and voltage measured after the fault and the load current and voltage of the $1 \sim 3$ cycles before the fault.

The formula is as follows:

$$
\left\{\begin{array}{l}
\Delta i_{*}=i_{k m}-i_{|0|} \\
\Delta u_{*}=u_{k m}-u_{|0|}
\end{array}\right.
$$


Combining formula (1),(3) (7),

the power frequency variation before R-SFCL started is the same as the fault component; the power frequency variation after R-SFCL started includes not only the fault component, also includes the influence of current limiting resistance; frequency variable impedance relay based on the conditions of application of superposition lose application condition.

Before R-SFCL started:

$\left\{\begin{array}{l}\dot{U}_{|0|}=\dot{E}_{s 1}-\dot{I}_{|0|} Z_{s} \\ \dot{U}_{\mathrm{F}|0|}=\dot{U}_{|0|}-\dot{I}_{|0|} Z_{k}\end{array}\right.$

After R-SFCL started:

$\left\{\begin{array}{l}\dot{U}_{L}=\dot{E}_{s 1}-\dot{I}_{L} Z_{s} \\ \dot{U}_{\mathrm{FR}[0]}=\dot{U}_{L}-\dot{I}_{L}\left(Z_{k}+R_{f c l}\right)\end{array}\right.$

According to the formula (3) $\sim(9)$, the $\Delta i_{*}$ calculation value based on memory data is too small, which leads to the smaller setting value of the work voltage $\Delta \dot{U}_{\mathrm{op}^{*}}$. The movements are shown in figures 6 and 7 .

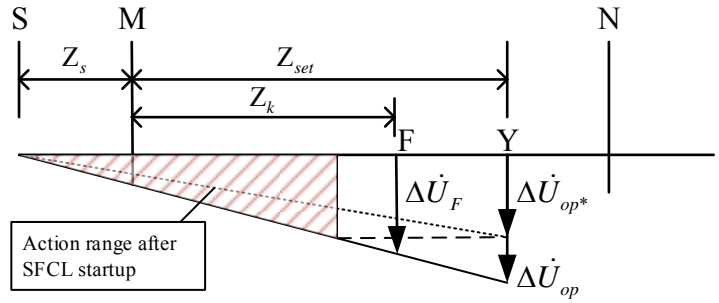

Fig. 6 ext(10)ernal directional fault voltage after R-SFCL started

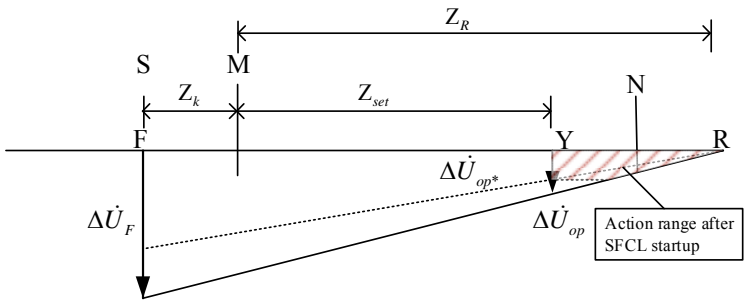

Fig. 7 reverse directional fault voltage after R-SFCL started

Same fault occurs in the same position, after SCFCL started, the working voltage $\Delta \dot{U}_{\text {op* }^{*}}$ calculated by power frequency variation based on memory data is smaller, if still using the original brake voltage, will lead to internal fault protection area is decreased or even completely out of action, the external fault protection provided high selectivity.

\section{Principle of Adaptive Current Fast Breaking Protection With RSFCL}

When there is no superconducting fault current limiter, the power frequency variation impedance relay criterion (3) can be rewritten as:

$$
\left|\dot{I}_{k}-\dot{I}_{L}\right| \geq \frac{k_{r e l} U_{N}}{\left|Z_{\Delta}+Z_{\text {set }}\right|}
$$

Where $Z_{\Delta}=-\frac{\Delta \dot{U}}{\Delta \dot{I}}$, when external directional fault occurs $Z_{\Delta}=Z_{s 1}$, when reverse directional fault occurs $Z_{\Delta}=-Z_{R}$.

The operation criterion of adaptive current quick breaking protection is:

$$
\left|\dot{I}_{k}\right| \geq \frac{k_{r e l} U_{N}}{\left|Z_{\Delta}+Z_{\text {set }}\right|}
$$


When the superconducting fault current limiter is installed, when positive direction fault occurs shown as Figure 8, from the terminal power $\mathrm{S}$ to the relay installation position $\mathrm{M}$, the circuit model before and after the fault has not changed, so the use condition of the superposition theorem is still satisfied.

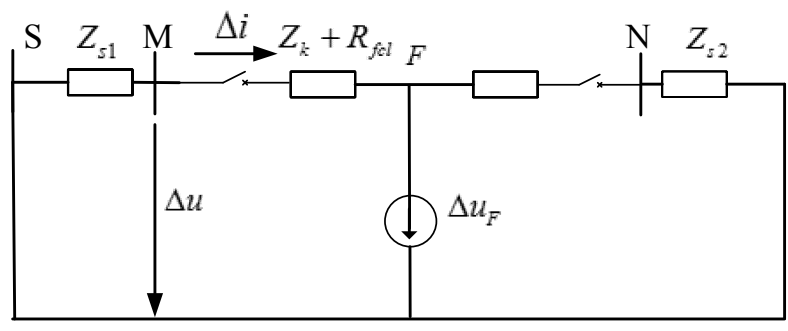

Deduce by Formula (7):

Fig. 8 fault component diagram of forward fault

$$
\Delta \dot{U}_{*}=-\Delta \dot{I}_{*} Z_{s 1}
$$

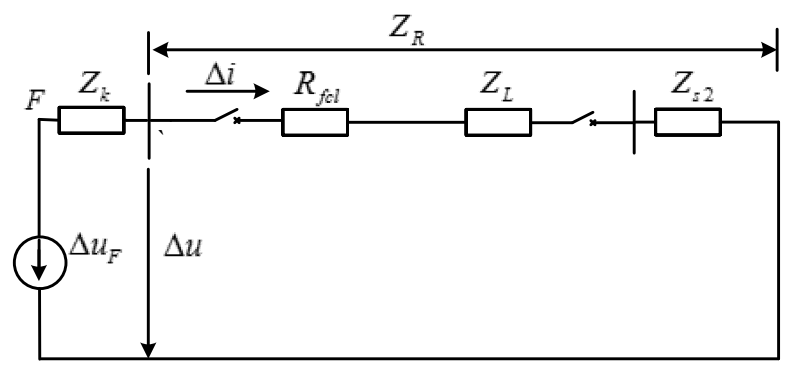

Fig. 9 fault component diagram of reverse fault

In reverse fault, $\Delta \dot{U}=\Delta \dot{I} Z_{R}$, The load current $\dot{I}_{|0|}$ recorded by memory element is bigger than real value, on the contrary The load voltage $\dot{U}_{|0|}$ recorded by memory element is smaller than real value.

$$
Z_{\Delta^{*}}=-\frac{\Delta \dot{U}_{*}}{\Delta \dot{I}_{*}}, Z_{\Delta^{*}}<0,\left|Z_{\Delta^{*}}\right|<Z_{R}
$$

Deduce by Formula (10) Error! The reference source was not found. action criterion of forward fault is as follow:

$$
\left|\dot{I}_{k}\right| \geq \frac{k_{r e l} U_{N}}{\left|Z_{\Delta^{*}}+Z_{s e t}+R_{f c l}\right|}
$$

Deduce by Formula (5) (9), in reverse fault:

$$
\left|\Delta \dot{I}\left(Z_{R}-Z_{\text {set }}-\mathrm{R}_{\text {fcl }}\right)\right|=\left|\dot{\mathrm{U}}_{F R[0]}\right| \leq k_{\text {rel }} \mathrm{U}_{N}
$$

Combining the formula (14), (15), an adaptive current fast tripping protection action criterion suiting R-SFCL is as follow:

$$
\left|\dot{I}_{k}\right| \geq \frac{k_{r e l} U_{N}}{\left|Z_{\Delta^{*}}+Z_{s e t}+R_{f c l}\right|}
$$

\section{Simulation Verification}

Build the mathematical model of R-SFCL on the PSCAD and establish a two terminal power supply model, as shown in figure 5 . The voltage at the sending end is $230 \mathrm{kV}$, and the voltage at the receiving end is $220 \mathrm{kV}$. The power impedance is: $r=0.01 \Omega, x=5.84 \Omega ; L_{A B}=100 \mathrm{~km} L_{B C}=80 \mathrm{~km}$, the line parameter is $r=0.08 \Omega / \mathrm{km}, x=0.417 \Omega / \mathrm{km}$, when the R-SFCL started $R_{f c l}=30 \Omega$. 


\section{Characteristics Analysis of Power Frequency Variation Impedance Relay}

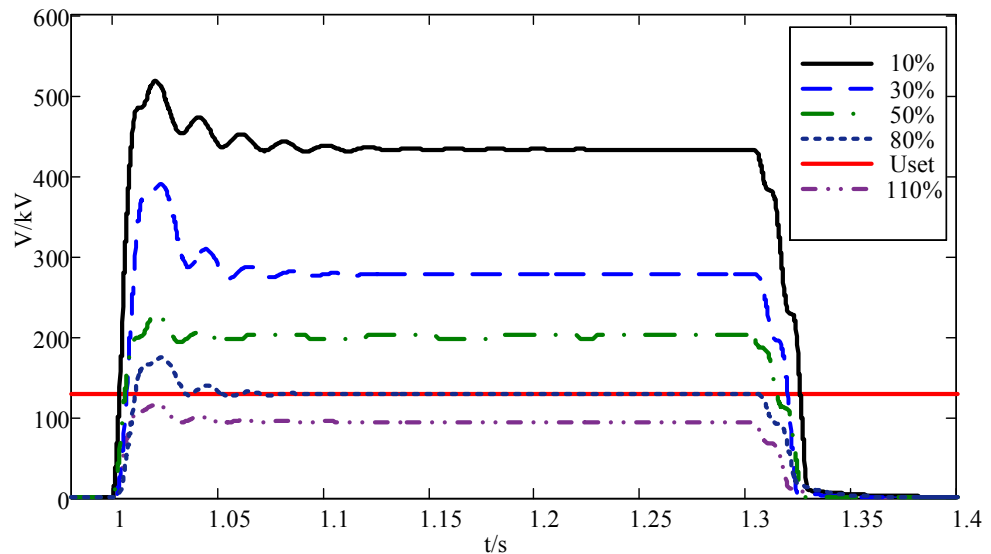

Fig 10 Action characteristics of power frequency variation impedance relay

Metal grounding fault occurs at $1 \mathrm{~s}$. The working voltage is shown in Figure 10. The protection range is $80 \%$ of the line, and the detailed action conditions are shown in Table 1. No fault outside the zone. It has good selectivity. R-SFCL reduced the range of motion in the back zone to $32 \%$.

Table 1 Action characteristics of power frequency variation impedance relay before and after

R-SFCL started

\begin{tabular}{|c|c|c|c|c|c|c|}
\hline \multicolumn{7}{|c|}{ act correctly(Y/N) } \\
\hline location & $-5 \%$ & $10 \%$ & $30 \%$ & $32 \%$ & $80 \%$ & $90 \%$ \\
\hline NoSFCL & $\mathrm{N}$ & $\mathrm{Y}$ & $\mathrm{Y}$ & $\mathrm{Y}$ & $\mathrm{Y}$ & $\mathrm{N}$ \\
\hline SFCL & $\mathrm{N}$ & $\mathrm{Y}$ & $\mathrm{Y}$ & $\mathrm{N}$ & $\mathrm{N}$ & $\mathrm{N}$ \\
\hline
\end{tabular}

\section{Performance Verification of Adaptive Current Protection Operation}

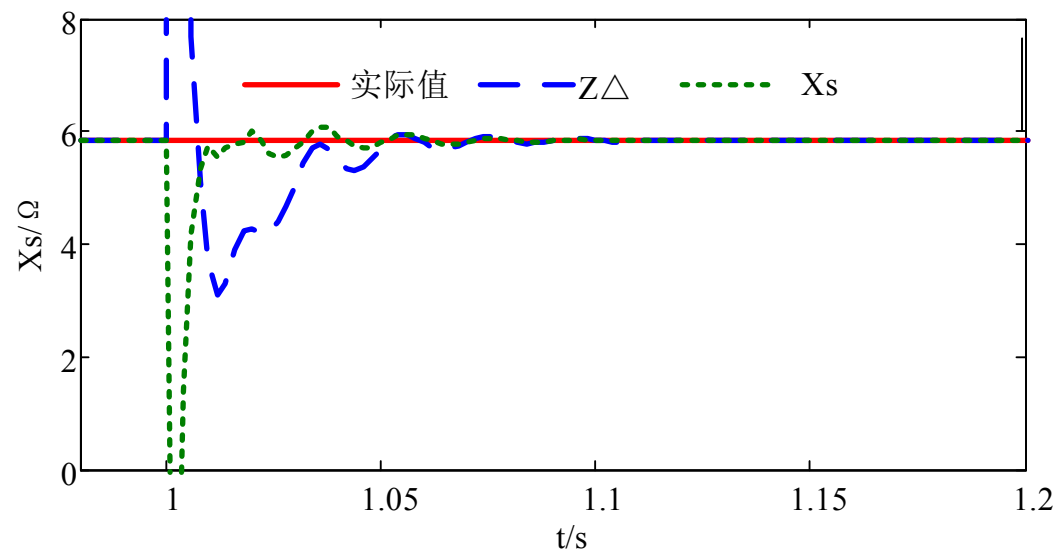

Fig 11 Additional impedance and equivalent internal resistance in internal faul

When the A phase occurs at the position of line $10 \%$, a metal grounding fault occurs in the $1 \mathrm{~s}$ phase. When the positive direction fault occurs, the calculated equivalent impedance and the actual impedance of the power supply are shown in figure 11 . After $20 \mathrm{~ms}$, the resistance value is calculated around the actual value. After $110 \mathrm{~ms}$, the equivalent internal resistance calculation is stable. Within a cycle with the error table 2 after fault, the results are not accurate, this is because the the time window of Fourier transform is about half a cycle to one cycle, the calculation results can accurately represent the system internal resistance only after all data in the window are the faulted data. Therefore, subject to the Fourier time window length, there is transient time during which the calculated value is inaccurate, one cycle later the error is less than 5.6\%, error between calculated additional impedance and real system resistance is smaller, the reliability of adaptive instantaneous current protection is quite high. 
Table 2 Calculation error analysis of equivalent impedance of power supply

\begin{tabular}{|c|c|c|c|c|c|}
\hline \multicolumn{5}{|c|}{ Actual equivalent impedance of power supply $\mathrm{Xs}=5.384 \Omega$} \\
\hline time/s & $\begin{array}{c}\text { CALC } \\
\text { value }\end{array}$ & err\% & time/s & $\begin{array}{c}\text { CALC } \\
\text { value }\end{array}$ & err\% \\
\hline 1.00 & 5.532 & -5.285 & 1.06 & 5.841 & 0.009 \\
\hline 1.01 & 5.672 & -2.888 & 1.07 & 5.842 & 0.024 \\
\hline 1.02 & 5.838 & -0.035 & 1.08 & 5.843 & 0.041 \\
\hline 1.03 & 5.808 & -0.562 & 1.09 & 5.843 & 0.041 \\
\hline 1.04 & 5.830 & -0.176 & 1.1 & 5.843 & 0.045 \\
\hline 1.05 & 5.836 & -0.074 & 1.11 & 5.843 & 0.044 \\
\hline
\end{tabular}

Table 3 action range of relay protection

\begin{tabular}{|c|c|c|c|c|c|c|c|}
\hline \multicolumn{2}{|c|}{ location } & $-5 \%$ & $10 \%$ & $30 \%$ & $32 \%$ & $80 \%$ & $90 \%$ \\
\hline No SFCL & $\mathrm{I}_{\text {set } 1}$ & $\mathrm{~N}$ & $\mathrm{Y}$ & $\mathrm{Y}$ & $\mathrm{Y}$ & $\mathrm{Y}$ & $\mathrm{N}$ \\
\hline SFCL & $\mathrm{I}_{\text {set } 1}$ & $\mathrm{~N}$ & $\mathrm{Y}$ & $\mathrm{Y}$ & $\mathrm{N}$ & $\mathrm{N}$ & $\mathrm{N}$ \\
\hline SFCL & $\mathrm{I}_{\text {set2 }}$ & $\mathrm{N}$ & $\mathrm{Y}$ & $\mathrm{Y}$ & $\mathrm{Y}$ & $\mathrm{Y}$ & $\mathrm{N}$ \\
\hline
\end{tabular}

$I_{\text {set } 1}$ is the original adaptive current setting threshold with current limiting resistance uncompensated, and the $I_{\text {set } 2}$ is the current threshold after compensation. After the current limiter is put into operation, the original protection range is obviously reduced. After the compensation, the adaptive current quick tripping protection can effectively restore the protection range.

Table 4 Fault position and the maximum transition resistance

\begin{tabular}{|c|c|c|c|}
\hline & \multicolumn{3}{|c|}{ Maximum transition resistance $/ \Omega$} \\
\hline & \multicolumn{2}{|c|}{ Without FCL } & FCL \\
\hline location & $\begin{array}{c}\text { impedance } \\
\text { relay }\end{array}$ & Adaptive current protection \\
\hline $1 \%$ & 30.9 & 39.5 & 19 \\
\hline $5 \%$ & 30.5 & 39 & 19 \\
\hline $10 \%$ & 30 & 38.5 & 18.5 \\
\hline $20 \%$ & 27 & 35 & 16.5 \\
\hline $30 \%$ & 22 & 30 & 13 \\
\hline $50 \%$ & 12 & 18 & 6 \\
\hline $70 \%$ & 5 & 8 & 3 \\
\hline $80 \%$ & 0.5 & 3 & 0.5 \\
\hline
\end{tabular}

Table 4 shows that the closer the fault location is to the protection and installation position, the stronger the transition resistance capability is. The adaptive current quick breaking protection has the ability of transition resistance, which is stronger than that of the power frequency sudden change impedance relay. After the fault current limiter is put into operation, the transition resistance capability of the adaptive current fast breaking protection is still obviously reduced, even if it has been compensated.

Table 5 Fault location and action sequence

\begin{tabular}{|c|c|c|c|}
\hline \multicolumn{4}{|c|}{ time/ms } \\
\hline \multirow{2}{*}{ location } & $\begin{array}{c}\text { impedance } \\
\text { relay }\end{array}$ & \multicolumn{2}{c|}{$\begin{array}{c}\text { Adaptive current } \\
\text { protection }\end{array}$} \\
\cline { 2 - 4 } & \multicolumn{2}{|c|}{ With out FCL } & FCL \\
\hline $1 \%$ & 2.50 & 3.51 & 3.61 \\
\hline $10 \%$ & 2.63 & 3.65 & 3.51 \\
\hline $30 \%$ & 2.67 & 2.48 & 2.76 \\
\hline $50 \%$ & 6.13 & 4.16 & 3.81 \\
\hline $70 \%$ & 7.98 & 4.21 & 3.81 \\
\hline $80 \%$ & 8.91 & 5.40 & 3.89 \\
\hline
\end{tabular}


Table 5 shows that the power frequency variable impedance relay has a good quick action, and the closer the fault location is to the protection installation position, the faster it is. The average operation time of the adaptive current quick breaking protection is no longer than that of the power frequency variation impedance relay, and the action time is hardly affected by the fault position.

\section{Conclusion}

1) The start-up of SFCL changes the circuit parameters, the power frequency variation includes not only the fault component, but also the influence of the current limiting resistor, Power frequency variation impedance relay based on the superposition theorem is not satisfied superposition condition.

2) This paper puts forward an adaptive current quick break protection based on power frequency variation. Research shows that the protection principle have a speed no slower than the power frequency variation impedance relay, and it has a stronger ability of transition resistance, what's more, its action time can not be affected by fault location. It provides a new protection solution for the power systems with current limiting equipment installed.

\section{Acknowledgements}

This paper is supported by National natural science foundation of China (No.51577077, No.51477090) and Science and Technology Project of State Grid Corporation of China (SGTYHT/15-JS-191).

\section{References}

[1] Xin Y, Gong W, Niu X, et al. Development of Saturated Iron Core HTS Fault Current Limiters [J]. IEEE Transactions on Applied Superconductivity, 2007, 17(2): 1760-1763.

[2] Weller R A, Campbell A M, Coombs T A, et al. Computer modelling of superconducting film type fault current limiters [J]. IEEE Transactions on Applied Superconductivity, 1999, 9(2): 1377-1380.

[3] Wei L U, Jin X. Test and application of power frequency variation distance protection [J]. Electric Power Automation Equipment, 2006.

[4] Bock J, Breuer F, Walter H, et al. CURL 10: development and field-test of a $10 \mathrm{kV} / 10 \mathrm{MVA}$ resistive current limiter based on bulk MCP-BSCCO 2212[J]. IEEE Transactions on Applied Superconductivity, 2005, 15(2): 1955-1960.

[5] Lin Y, Juengst K P. Modeling and simulation of high temperature resistive superconducting fault current limiters [J]. IEEE Transactions on Applied Superconductivity, 2004, 14(2): 839-842.

[6] Hyun O B, Cha S D, Kim H R, et al. Shunt-Assisted Simultaneous Quenches in Series-Connected Resistive SFCL Components [J]. IEEE Transactions on Applied Superconductivity, 2003, 13(2): 2060-2063.

[7] Jiale S, Fangming H E, Jiao Z, et al. Research on the Characteristics of Distance Element Based on the Power-frequency Voltage and Current Variation [J]. Proceedings of the Csee, 2010, 30(28): 59-65. 